\title{
A microRNA expression signature as a predictor of survival for colon adenocarcinoma
}

\author{
M. XU, Y. KUANG, M. WANG, X. HAN, Q. YANG* \\ Department of Pathogenobiology, College of Basic Medical Sciences, Jilin University, Changchun 130021, Jilin Province, China \\ ${ }^{*}$ Correspondence: yangq@jlu.edu.cn
}

Received July 5, 2016 / Accepted August 31, 2016

\begin{abstract}
Colon cancer is a major cause of cancer mortality worldwide and most colon cancers are adenocarcinoma. MicroRNA (miRNA) expression signature has been shown to be able to predict progression and prognosis of various cancers. The aim of our study was to explore a novel signature of microRNA expression for predicting survival of colon adenocarcinoma patients. By analyzing the miRNA expression profiles and clinical information of 329 colon adenocarcinoma patients derived from The Cancer Genome Atlas database. 129 miRNAs were identified to be expressed differentially between the cancer and adjacent tissues. Among them, 27 miRNAs were found to be associated with the corresponding clinical characteristics of the patients. Furthermore, 7 miRNAs (let-7a-2, mir-32, mir-181a-1, mir-197, mir-328, mir-505 and mir-652) were found to be significantly correlated with the patient survival. The risk established by the 7-miRNA signature we built was proved be an independent prognostic factor (Hazard ratio $[\mathrm{HR}]=2.048 ; 95 \% \mathrm{CI}=1.144-3.664 ; \mathrm{p}, 0.016$ ). In summary, our study identified miRNAs correlated with progression and prognosis of colon adenocarcinoma and built a 7-microRNA expression signature for prediction of the survival of the patients with colon adenocarcinoma.
\end{abstract}

Key words: colon cancer, biomarker, microRNA, survival

Colon cancer is a common gastrointestinal cancer with a significant threat to the patient health and the third leading cause of cancer mortality in the United States [1]. Prognosis for patients with colon cancer has significantly improved in past decades with technological advances in early detection and intervention [2]. Although, prognosis remains poor for those with advanced stage colon cancer even they received standard care treatment including surgery, chemotherapy and radiotherapy [3-5]. Colon cancer has various histological subtypes and $90 \%$ of them are adenocarcinoma [2, 6]. Identifying novel biomarkers at a molecular level to predict prognosis and improve treatment outcome for afflicted patients would have a very important practical significance.

MicroRNAs (miRNAs) are a group of 19 to 25 nucleotides in length small non-coding RNAs that regulate gene expression at the post-transcriptional level through binding to the sequences of their target mRNAs' 3'untranslated region [7]. They participate in regulating many cellular processes such as proliferation, differentiation, and apoptosis $[8,9]$. Acumulating studies have implied that miRNAs are mutated or expressed aberrantly in human cancers, exerting critical functions in the pathogenesis of cancers $[10,11]$. Expression signatures of miRNAs have been proposed to be effective biomarkers for detection, intervention and prognosis of cancers $[12,13]$. The prognostic role of miRNAs' expressions in colon cancer has been reported [14-17]. For example, higher expression of miR-29a in stage II colon cancer was associated with a longer disease-free survival of the patients $[17,18]$, and higher miR-21 expression in colon adenocarcinoma was associated with low survival rate and resistance to chemotherapy [15]. In this study, we analyzed miRNA expression data and corresponding clinical information of 329 colon adenocarcinoma patients from the latest gathered data in The Cancer Genome Atlas (TCGA) database, and found that some miRNAs were expressed differentially in colon adenocarcinoma. We then generated a novel miRNA expression signature model that could be used to predict survival of the patients.

\section{Patients and methods}

Patient information and miRNA microarray data. The miRNA expression data and the corresponding clinical in- 
formation of the patients with colon cancer were downloaded from the TCGA data portal (http://cancergenome.nih.gov/) in October 2015. The downloaded file contained 444 cases of miRNA expression and 459 cases of clinical information. We screened the data from these cases, and selected the patients for the present study according to the following criteria: (1) the tumor histological type was colon adenocarcinoma; (2) the clinical information was complete and evaluable; (3) the patients didn't die for other non-cancer reasons during the following-up investigation. Overall, 329 patients were enrolled in the present study, and their demographic characteristics and clinical information were summarized in Table 1. Among the 329 patients (Cohort T), 8 patients provided the corresponding adjacent non-tumor tissues (Cohort M). The TCGA project collected and processed patient data following the data access policies approved by their ethics committee, so no further ethical approval was required for this study.

The expression data of the miRNAs were obtained by miRNA sequencing performed with the Illumina Genome Analyzer and HiSeq platforms (Illumina Inc, San Diego, CA, USA). Raw expression data were standardized into level 3 data with the expression quantity demonstrated as reads per million (RPM). We downloaded the level 3 data and analyzed them with BRB-Array tools (version 4.4.0) developed by Dr. Richard Simon and the BRBA-array Tools Development Team [19]. We excluded non-qualified miRNAs from the data according to the following criteria: (1) the expression was less than 1 RPM in at least $90 \%$ of the samples; (2) the expression had less than 1.5 folds changes from the median value in at least $80 \%$ of the samples. Then, RNAseq expression data $\log 2$ transformed were conducted to standardize the expression values of each filtered miRNA [20].

Target gene prediction and pathway analysis. DIANAmirPath [21] tools were employed to do pathway analysis of miRNAs signature. Target genes were predicted by the microT-CDS algorithm and some experimentally validated miRNA interactions were derived from the DIANA-TarBase database. KEGG pathway enrichment and GO annotation of these target genes were conducted by the mirPath v. 3 with default settings.

Statistical analysis. The continuous variables were presented as mean \pm standard deviation (SD) and the categorical variables were expressed as counts and percentages. Chisquare test was used to analyze the different distribution of clinical variables (gender, AJCC stage, depth of invasion, lymph node invasion and distant metastasis) between Cohort $\mathrm{M}$ and Cohort $\mathrm{T}$, while Student $\mathrm{t}$ test was used to examine the difference of age. To determine the difference of miRNA expression between cancerous and matched noncancerous tissues, paired-sample $t$ test was conducted (significant $p$-value was set as 0.001 ). The unpaired t-test was employed to analyze the expression levels of miRNAs between different clinicopathological groups (significant $p$-value was set as 0.01 ).

To explore the relationship between miRNA expression and patients' survival time, the univariate Cox proportional hazards regression model was conducted (significant $p$-value was set as $0.001)$. After the significant miRNAs were selected, the KaplanMeier method and the log-rank test were performed to study the distribution of survival time in different expression states. Expression value of the miRNAs and survival status of the patients were used to compute the risk score, and an expression signature was generated by the principal component model. For further exploring prognostic values of the microRNA expression signature, the univariate Cox regression analysis was conducted to identify the effects of risk score (high risk vs low risk), AJCC stage (stage III+IV vs stage I+II), depth of invasion ( $\mathrm{T} 3+\mathrm{T} 4$ vs $\mathrm{T} 1+\mathrm{T} 2)$, lymph node invasion $(\mathrm{N} 1+\mathrm{N} 2$ vs $\mathrm{N} 0)$ and distant metastasis (M1 vs M0) on patient survival. Then, multivariate Cox regression analysis was applied to combine the significant factors ( $p$-value $<0.05$ in the univariate Cox regression analysis). The results generated by Cox regression analysis were expressed as hazard ratio (HR) and $95 \%$ confidential interval (95\% CI). Unless specifically indicated, all tests were two-sides and $p$-value $<0.05$ was regard as statistically significant. All the statistical analysis was performed by the SPSS 19 (IBM, USA) and BRB-Array Tools 4.0.

Table 1. Clinical characteristics of patients with colon adenocarcinoma

\begin{tabular}{|c|c|c|c|}
\hline Category & $\begin{array}{c}\text { Cohort M } \\
(\mathrm{n}=8)\end{array}$ & $\begin{array}{r}\text { Cohort } \mathrm{T} \\
(\mathrm{n}=329)\end{array}$ & $P_{\text {value }}{ }^{a}$ \\
\hline Age & $75.4 \pm 15.2$ & $66.9 \pm 13.1$ & 0.013 \\
\hline Gender & & & 0.154 \\
\hline Male & 6 & 152 & \\
\hline Female & 2 & 177 & \\
\hline AJCC stage & & & 0.768 \\
\hline I & 1 & 53 & \\
\hline II & 4 & 132 & \\
\hline III & 1 & 91 & \\
\hline IV & 2 & 45 & \\
\hline NA & 0 & 8 & \\
\hline Tumor size & & & 0.946 \\
\hline $\mathrm{T} 1$ & 0 & 9 & \\
\hline $\mathrm{T} 2$ & 1 & 56 & \\
\hline T3 & 6 & 229 & \\
\hline T4 & 1 & 35 & \\
\hline Lymph node & & & 0.669 \\
\hline No & 6 & 197 & \\
\hline N1 & 1 & 80 & \\
\hline $\mathrm{N} 2$ & 1 & 52 & \\
\hline Metastasis status & & & 0.688 \\
\hline M0 & 6 & 253 & \\
\hline M1 & 2 & 45 & \\
\hline MX & 0 & 26 & \\
\hline NA & 0 & 5 & \\
\hline Vital status & & & 0.661 \\
\hline Live & 6 & 264 & \\
\hline Dead & 2 & 65 & \\
\hline
\end{tabular}




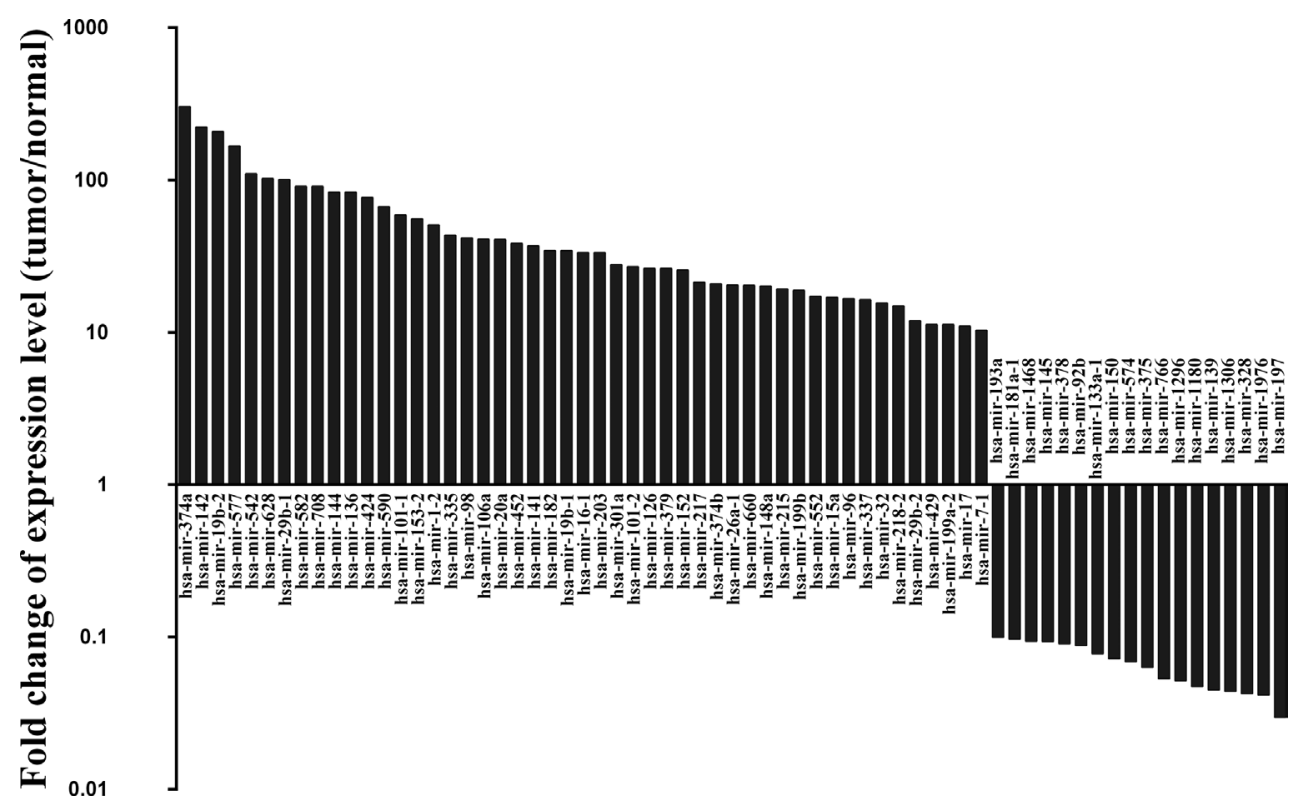

Figure 1. Differentially expressed microRNAs between colon adenocarcinoma and adjacent tissues with fold-change $\geq 10$.

A

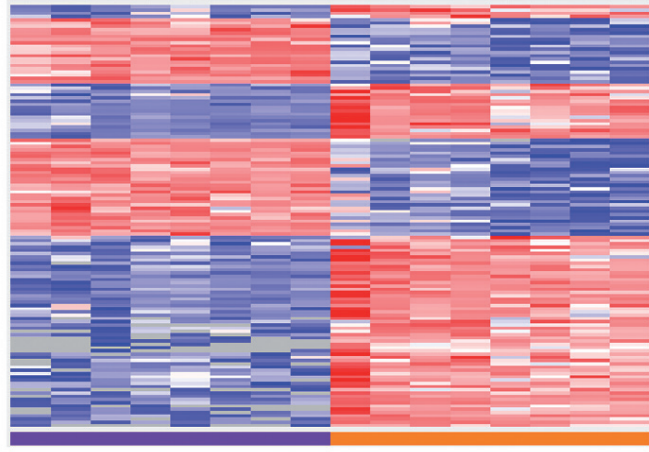

B

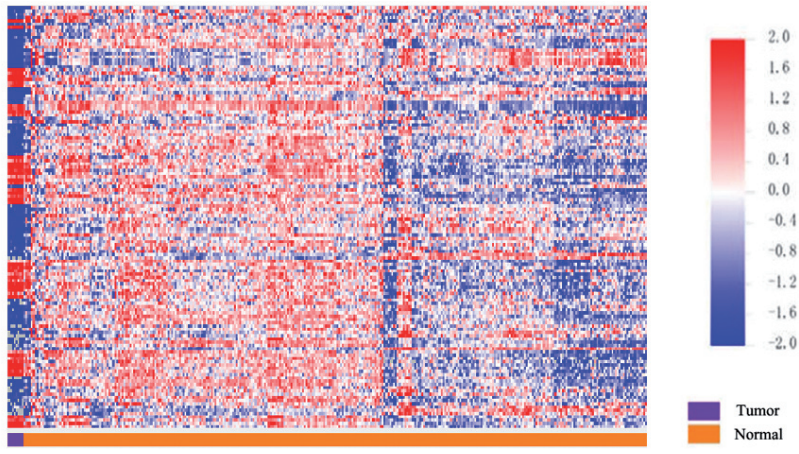

Figure 2. Unsupervised hierarchical cluster analysis of 129 differentially expressed miRNAs. A. Unsupervised hierarchical cluster analysis of 129 differentially expressed miRNAs in paired samples. B. Unsupervised hierarchical cluster analysis of 129 differentially expressed miRNAs in unpaired samples.

\section{Results}

Patient characteristics. There were a total of 329 patients enrolled in this study and among them (Cohort T), 8 patients provided corresponding the adjacent tissues (Cohort $\mathrm{M}$ ). All of these patients were clinically diagnosed with colon adenocarcinoma. Their ages were $66.9 \pm 13.1($ mean \pm SD) years old, and the follow-up time was $30.8 \pm 26.2$ (mean \pm SD) months. Overall, 14 (4.3\%) patients' follow-up time were less than 31 days and 46 (14.0\%) patients died after the mean follow-up time. The detailed demographic and clinical information with their distributions between the two cohorts are summarized in Table 1.

Differential expression analysis of miRNA. There were a total of 129 miRNAs expressed differentially between the cancer and the matched adjacent tissues ( $p$-value $<0.001)$. Among these 129 miRNAs, 80 miRNAs (61.5\%) were up-regulated in the cancer tissues, while the remaining 49 miRNAs $(38.5 \%)$ were downregulated (Table S1). In consideration of the fold change, 67 of them expressed a greater than ten-fold in the transformed values (Figure 1). In addition, the unsupervised hierarchical clustering could discriminate the cancer and the normal class clearly with these differentially expressed miRNAs (Figure 2). Besides, class comparison analysis was applied to found out miRNAs associated with cancer progression. A total of 27 differentially expressed miRNAs were identified to be associated with the corresponding clinical characteristics of the patients. Among them, 4 miRNAs was associated with AJCC tumor stage, 5 with pathologic T, 9 with pathologic $\mathrm{N}$, and 9 with pathologic $\mathrm{M}$ (Table S2).

MiRNA expression associated with patient survival. Seven miRNAs (let-7a-2, mir-32, mir-181a-1, mir-197, mir- 
328 , mir-505 and mir-652) were identified to be related to the survival of the patients with colon adenocarcinoma by the univariate Cox regression analysis (Table 2). Kaplan-Meier survival curves indicated that all of them were risky miRNAs (Figure 3). Then, a seven-miRNA expression signature was obtained by the principal component analysis with Cox pro-
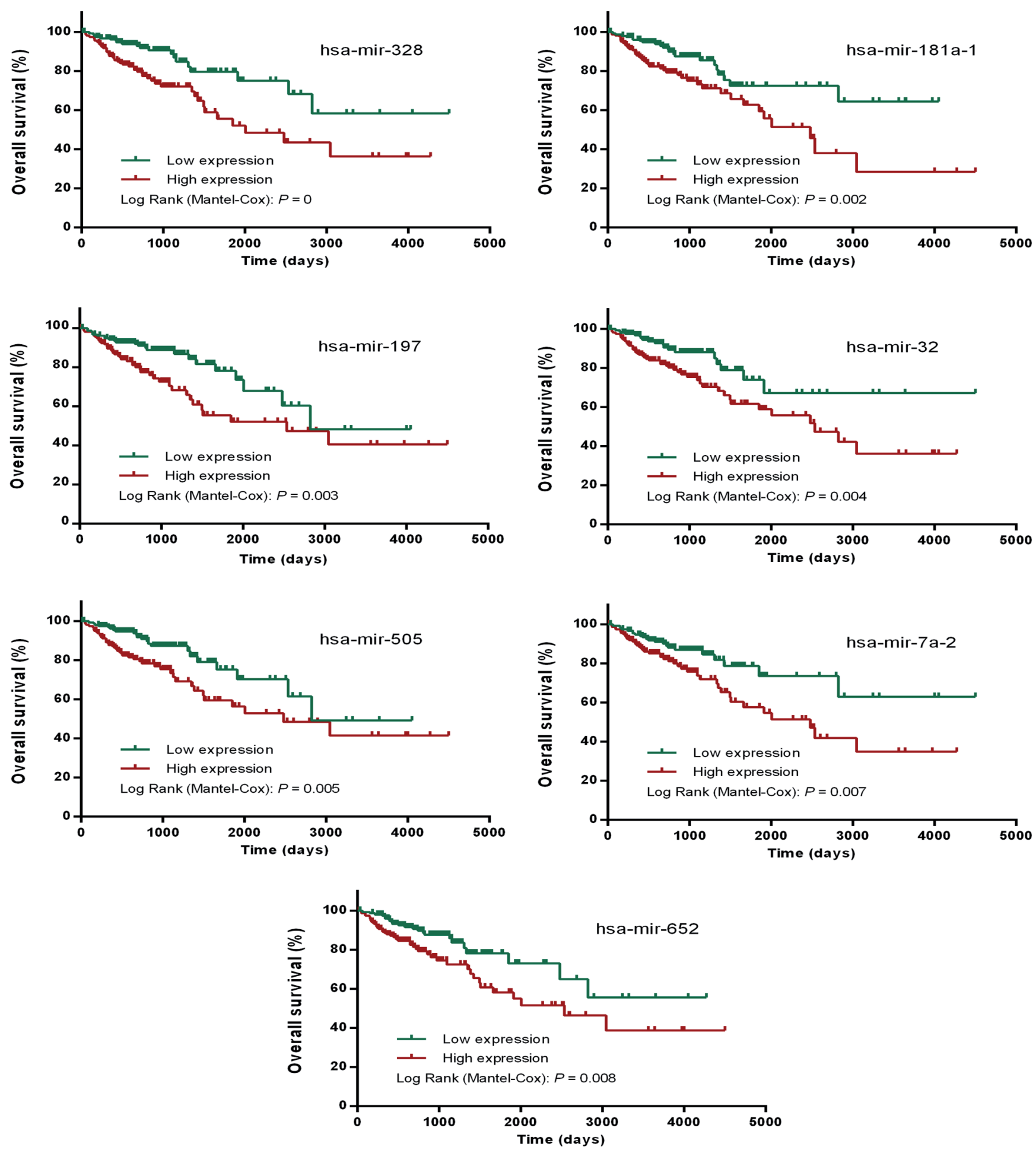

Figure 3. Kaplan-Meier survival curves for 7 survival related miRNAs. All miRNAs (hsa-mir-328, hsa-mir-181a-1, hsa-mir-197, hsa-mir-32, hsa-mir-505, hsa-let-7a-2 and hsa-mir-652) were negatively associated with overall survival. (Horizontal axis: overall survival time; vertical axis: survival function). 
Table 2. Univariate analysis of miRNAs associated with overall survival in colon adenocarcinoma patients.

\begin{tabular}{lccc}
\hline MiRNAs & HR & 95\% CI & P value $^{\mathrm{a}}$ \\
\hline let-7a-2 & 1.419 & $1.097-1.835$ & $\mathbf{0 . 0 0 8}$ \\
mir-32 & 1.465 & $1.120-1.916$ & $\mathbf{0 . 0 0 5}$ \\
mir-181a-1 & 1.483 & $1.146-1.919$ & $\mathbf{0 . 0 0 3}$ \\
mir-328 & 1.574 & $1.209-2.049$ & $\mathbf{0 . 0 0 1}$ \\
mir-197 & 2.11 & $1.266-3.518$ & $\mathbf{0 . 0 0 4}$ \\
mir-505 & 1.439 & $1.112-1.862$ & $\mathbf{0 . 0 0 6}$ \\
mir-652 & 1.401 & $1.085-1.809$ & $\mathbf{0 . 0 1}$ \\
\hline
\end{tabular}

HR hazard ratio; CI confidential interval.

${ }^{a}$ Statistical significant result (in bold)

portional hazards regression [22]. Risk score for each patient was computed by a math formula $\sum$ iwi xi -7.679485 where wi and xi are the weight and logged miRNA expression for the i-th miRNA (Risk score $=(0.148126 \mathrm{x}$ logged expression of hsa-mir-197) $+(0.123695$ x logged expression of hsa-mir-328) $+(0.186403 \times$ logged expression of hsa-mir-505 $)+(0.190766$ $\mathrm{x}$ logged expression of hsa-mir-32) $+(0.144632 \mathrm{x}$ logged expression of hsa-let-7a-2 $)+(0.110015 \mathrm{x}$ logged expression of hsa-mir-181a-1 $)+(0.241215 \mathrm{x}$ logged expression of hsa-mir$652)-7.679485$ ). A patient would be deem as high (low) risk if his risk score was larger (smaller) than 0.011828 .

Validation of the 7-miRNA signature as an independent prognostic factor. Clinical parameters (age, gender, AJCC tumor stage, pathologic $\mathrm{T}$, pathologic $\mathrm{N}$ and pathologic $\mathrm{M}$ ) and the 7-miRNAs signature in the patients with colon adenocarcinoma were conducted the univariate Cox regression analyses. The result indicated AJCC tumor stage $(\mathrm{P}=0.001)$, pathologic $\mathrm{T}(\mathrm{P}=0.044)$, pathologic $\mathrm{N}(\mathrm{P}=0.0001)$, pathologic $\mathrm{M}(\mathrm{P}=$ $0.0001)$ and risk score $(P=0.001)$ were significantly associated with survival of the patients (Table 3). Then, Kaplan-Meier survival curves demonstrated the distribution of survival time in different states of all significant variables (Figure 4). Furthermore, the 7-miRNAs signature $(\mathrm{HR}=2.048$; 95\% CI $=1.144-3.664 ; \mathrm{p}, 0.016)$ and pathologic $\mathrm{M}(\mathrm{HR}=1.686 ; 95 \%$ $\mathrm{CI}=1.196-2.375 ; \mathrm{p}, 0.003)$ passed the multivariate Cox regression analysis with all significant variables to be proven as an independent prognostic factors (Table 3 ).
Target gene prediction and pathway enrichment analysis. A summary of 1773 target genes of the 7 miRNAs in the signature were predicted by the microT-CDS algorithm. These target genes were then subjected to the GO annotation and KEGG analyses by DIANA-mirPath v.3. The GO annotation showed these target genes' functions were related to biosynthetic processes, cellular protein modification processes, nucleic acid binding transcription factor activity, and so on (Table 4). Besides, the results of KEGG analyses demonstrated that these target genes were mostly associated with cancerrelated pathways such as the Wnt signaling pathway, the p53 signaling pathway and the colorectal cancer signaling pathway. More pathways are listed on Table 4.

\section{Discussion}

Colon adenocarcinoma is the most prevalent subtype of colon cancer with highly variable clinical features $[2,23,24]$. Traditional models to predict patient survival are primarily established on imaging and pathohistologic examination without disease information at the molecular level $[25,26]$. Aberrant expression of miRNAs have been documented to be highly correlated with cancer pathogenesis and have potential to be used as a predictor for patient prognosis $[23,27,28]$. In this study, we analyzed the aberrant miRNA expression profiles in colon adenocarcinoma with the aim to find a miRNA expression signature which could serve as an independent predictor of survival for the patients with the cancer.

As a family of short, single-stranded and non-coding endogenous RNAs, miRNAs can regulate gene expression at the post-translational level. They are involved in various biological processes through binding to 3'untranslated regions of their target genes $[29,30]$. Emerging evidence has suggested that miRNAs play an important role in the development and progression of cancers, and identification of miRNA biomarkers is becoming an important field in cancer research $[12,13]$. In fact, a number of miRNAs were reported to be correlated with the prognosis of colon adenocarcinoma. Schetter et al. reported that higher miR-21 expression in colon adenocarcinoma tissue was associated with a poor prognosis and resistance to chemotherapeutic drug [15]. Brenner et al. demonstrated that higher expression of miR-29a was associated with a longer disease-free

Table 3. Univariate and multivariate analysis of parameters associated with overall survival.

\begin{tabular}{|c|c|c|c|c|c|}
\hline & & \multicolumn{2}{|c|}{ Univariate analysis } & \multicolumn{2}{|c|}{ Multivariate analysis } \\
\hline & & HR (95\% CI) & P value ${ }^{a}$ & HR (95\% CI) & P value ${ }^{a}$ \\
\hline 7-miRNA Signature & High risk vs. Low risk & $2.583(1.498-4.454)$ & 0.001 & $2.048(1.144-3.664)$ & 0.016 \\
\hline AJCC Pathological Stage & III + IV vs. I + II & $1.521(1.178-1.964)$ & 0.001 & $1.144(0.575-2.277)$ & 0.702 \\
\hline AJCC Pathological T & $\mathrm{T} 3+\mathrm{T} 4$ vs. $\mathrm{T} 1+\mathrm{T} 2$ & $1.603(1.013-2.534)$ & 0.044 & $1.767(0.853-3.661)$ & 0.126 \\
\hline AJCC Pathological N & $\mathrm{N} 1+\mathrm{N} 2$ vs. N0 & $1.597(1.246-2.048)$ & $<0.001$ & $1.120(0.598-2.099)$ & 0.723 \\
\hline AJCC Pathological M & M1 vs. M0 & $2.132(1.603-2.841)$ & $<0.001$ & $1.686(1.196-2.375)$ & 0.003 \\
\hline
\end{tabular}

AJCC American Joint Committee on Cancer; HR hazard ratio; CI confidential interval; vs. versus

${ }^{\text {a }}$ Statistical significant results (in bold) 
survival of stage II colon cancer patients [17]. However, exact biological functions and potential prognostic characteristics of miRNAs in colon adenocarcinoma remain to be elucidated.

In the present study, we explored genome wide miRNA expression profiles and the corresponding clinical data of
329 colon adenocarcinoma patients selected from the TCGA database. We identified 129 miRNAs that were differentially expressed between the cancer and adjacent tissues. Robustness of the classifier with all these differentially expressed miRNAs were validated in unpaired conditions. Among
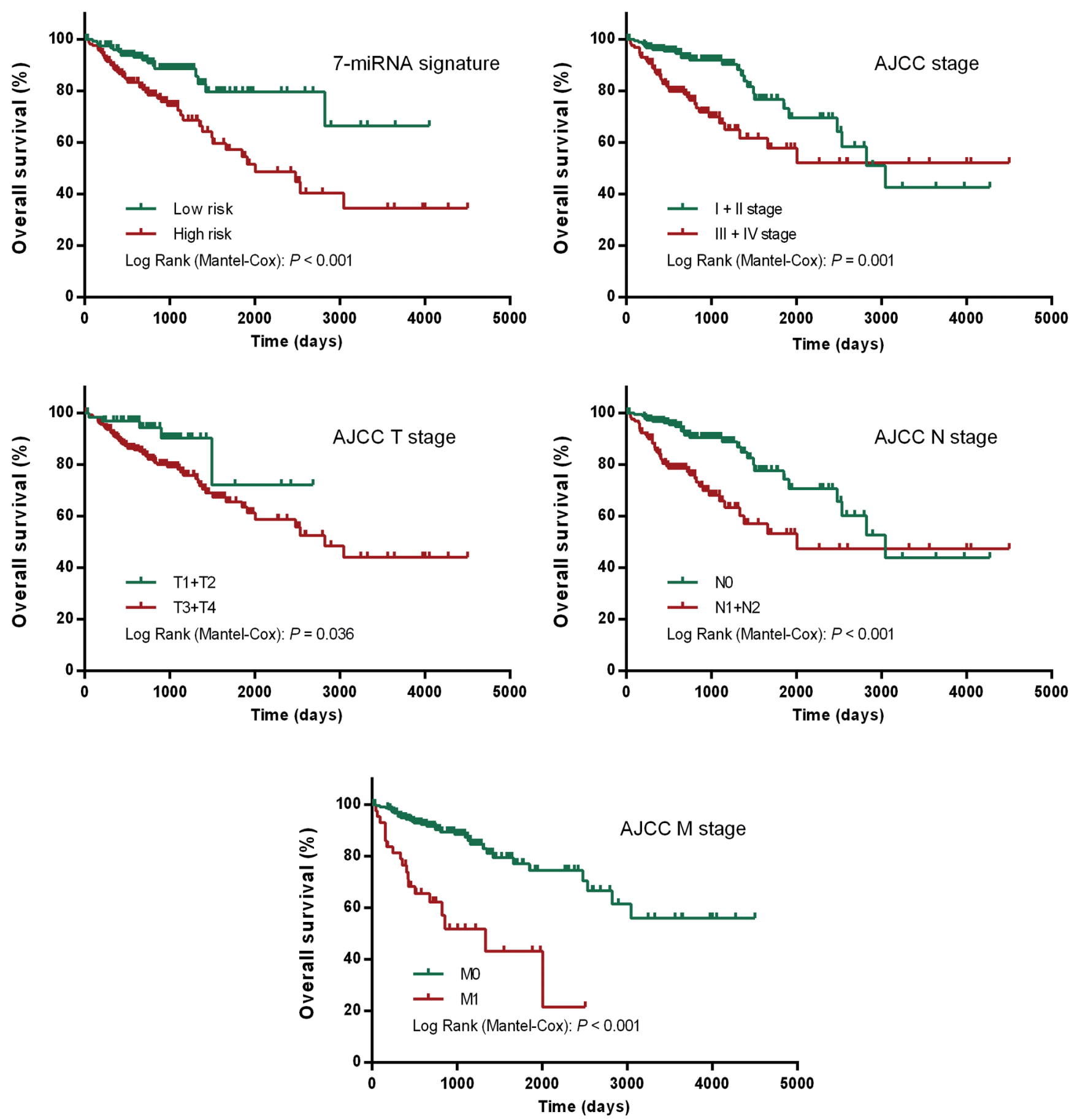

Figure 4. Kaplan-Meier survival curves for colon adenocarcinoma patients. 329 colon adenocarcinoma patients were compared in two groups according to: 7-miRNA signature (high risk vs. low risk); AJCC pathological (III + IV vs. I + II stage); AJCC T stage (T3+T4 vs. T1+T2); AJCC N stage (N1+N2 vs. N0) and AJCC M stage (M1 vs. M0). (Horizontal axis: overall survival time; Vertical axis: survival function). 
Table 4. GO and KEGG analysis of the seven miRNAs' target genes.

\begin{tabular}{|c|c|c|c|}
\hline GO Analysis & Number of miRNAs & Number of genes & P-value \\
\hline Organelle (GO:0043226) & 7 & 889 & $2.56 \mathrm{E}-52$ \\
\hline Ion binding (GO:0043167) & 7 & 623 & $1.64 \mathrm{E}-51$ \\
\hline Cellular nitrogen compound metabolic process (GO:0034641) & 7 & 497 & $3.92 \mathrm{E}-46$ \\
\hline Biosynthetic process (GO:0009058) & 7 & 407 & $1.27 \mathrm{E}-29$ \\
\hline Cellular protein modification process (GO:0006464) & 7 & 254 & $8.10 \mathrm{E}-23$ \\
\hline Molecular_function (GO:0003674) & 7 & 1403 & $1.82 \mathrm{E}-17$ \\
\hline Protein binding transcription factor activity (GO:0000988) & 7 & 73 & $2.06 \mathrm{E}-14$ \\
\hline Gene expression (GO:0010467) & 7 & 71 & $3.67 \mathrm{E}-13$ \\
\hline Nucleoplasm (GO:0005654) & 7 & 138 & $3.67 \mathrm{E}-13$ \\
\hline Nucleic acid binding transcription factor activity (GO:0001071) & 7 & 117 & $9.95 \mathrm{E}-13$ \\
\hline Cellular_component (GO:0005575) & 7 & 1394 & $3.19 \mathrm{E}-11$ \\
\hline Enzyme binding (GO:0019899) & 7 & 137 & $1.55 \mathrm{E}-10$ \\
\hline Cellular component assembly (GO:0022607) & 7 & 136 & $3.30 \mathrm{E}-10$ \\
\hline Protein complex (GO:0043234) & 7 & 340 & $5.99 \mathrm{E}-10$ \\
\hline Catabolic process (GO:0009056) & 7 & 183 & $9.91 \mathrm{E}-10$ \\
\hline KEGG Pathway Analysis & Number of miRNAs & Number of genes & P-value \\
\hline Wnt signaling pathway & 7 & 26 & $2.29 \mathrm{E}-08$ \\
\hline Glycosaminoglycan biosynthesis - heparan sulfate / heparin & 3 & 5 & $5.58 \mathrm{E}-04$ \\
\hline Adherens junction & 5 & 11 & $3.29 \mathrm{E}-03$ \\
\hline Focal adhesion & 5 & 22 & $7.26 \mathrm{E}-03$ \\
\hline ErbB signaling pathway & 5 & 11 & $7.58 \mathrm{E}-03$ \\
\hline PI3K-Akt signaling pathway & 5 & 32 & $8.61 \mathrm{E}-03$ \\
\hline Drug metabolism - cytochrome P450 & 2 & 3 & $1.43 \mathrm{E}-02$ \\
\hline VEGF signaling pathway & 6 & 9 & $1.83 \mathrm{E}-02$ \\
\hline p53 signaling pathway & 5 & 9 & $2.32 \mathrm{E}-02$ \\
\hline TGF-beta signaling pathway & 4 & 10 & $2.60 \mathrm{E}-02$ \\
\hline RNA transport & 7 & 15 & $3.04 \mathrm{E}-02$ \\
\hline MAPK signaling pathway & 6 & 26 & $3.17 \mathrm{E}-02$ \\
\hline Colorectal cancer & 4 & 9 & $3.98 \mathrm{E}-02$ \\
\hline HIF-1 signaling pathway & 4 & 12 & 4.37E-02 \\
\hline
\end{tabular}

(A) GO analysis of the target gene; (B) KEGG analysis of the target gene.

these 129 miRNAs, 67 miRNAs had more than ten folds change in expression levels. With regard to the clinical pathological feature, 4 of the aberrantly expressed miRNAs were identified to be associated with AJCC tumor stage, 5 with pathologic T, 9 with pathologic $\mathrm{N}$, and 9 with pathologic $\mathrm{M}$. Subsequently, seven miRNAs (let-7a-2, mir-32, mir-181a-1, mir-197, mir-328, mir-505 and mir-652) were ascertained to be significantly associated with overall survival of the patients with colon adenocarcinoma. Kaplan-Meier survival curves indicated that all of them were risky miRNAs. After the stepwise univariate Cox regression analysis and the multivariate Cox regression analysis, a seven-miRNAs signature was proved to be an independent prognostic factor. Among these prognosis associated miRNAs, mir-197 and mi-328 were previously reported to be related with colon cancer. Zhou et al reported downregulation of mir-197 in colon cancer cells upon administration of chemotherapeutics in vitro [31]. Xu et al documented that miR-328 could be interacting with ABCG2 gene to overcome drug resistance in colorectal cancer cells [32]. Some of the miRNAs in the signature were also to be associated other cancers. Lower expression of let-7a-2 and mir-32 was identified to be correlated with poor survival of lung cancer $[33,34]$. MiRNA-32 was reported to promote hepatocellular carcinoma cell proliferation, migration and invasion [35]. As a member of the mir-181 family, expression of mir-181a-1 proved to be an independent diagnostic indicator jointed with KAT2B gene expression in gastric cancer [36]. The KEGG enrichment analysis indicated the 7 miRNAs in the signature could regulate important cancer related pathways such as Wnt signaling pathway, the p53 signaling pathway, and the colorectal cancer signaling pathway. More biological functions of these miRNAs in colon adenocarcinoma remain to be clarified.

Some limitations should be acknowledged in interpreting the above results. First, there were 329 cancer tissues but only 8 paired cancer adjacent tissues conducted to identify the differentially expressed miRNAs between them. The sample numbers of the latter were relatively small which could re- 
duce the statistical power. Besides, although we selected and analyzed the data strictly, external biological and clinical experiment still need to be performed to validate the prognostic model. Among those prognosis related miRNAs, 6 were downregulated (let-7a-2, mir-181a-1, mir-197, mir-328, mir505 and mir-652) in tumors, and 1 was upregulated (mir-32). But, they were all identified to be risky miRNAs by Cox regression analysis and the Kaplan-Meier method. The following reasons may explain the controversial results. First, although oncogenes were usually highly expressed in tumors, no theory exists to validate the universality of their relationship. Second, some miRNAs may play different roles at different stages of tumor development like transforming growth factor-beta (TGF- $\beta$ ) that functions as a tumor suppressor in normal and early-stage cancers and as a tumor promoter in their late-stage counterparts $[37,38]$. Indeed, Meng et al. reported that some miRNAs are expressed in a wave-like manner during carcinogenesis [39]. Finally, compared with the survival analysis, the number of samples was relatively small in paired class comparison for screening differentially expressed genes, and this could reduce the statistical power and generate some false positive results.

In summary, by analyzing an independent colon adenocarcinoma patient cohort derived from the TCGA database, our study identified a seven-miRNA expression signature which could serve as an independent prognostic factors to predict survival of the patients with colon adenocarcinoma.

Acknowledgments: We thank The Cancer Genome Atlas (TCGA) project for providing data. Support for the study was provided by the National Natural Science Foundation of China (No. 31571443 to QY), the Jilin Provincial Science and Technology Department (No. 20140414031GH and No. 20150101121JC to QY), and the Health and Family Planning Commission of Jilin Province (No. 2014 Z068 to QY).

\section{References}

[1] SIEGEL R, DESANTIS C, JEMAL A. Colorectal cancer statistics, 2014. CA Cancer J Clin 2014; 64: 104-117. https:/doi. org/10.3322/caac. 21220

[2] BRENNER H, KLOOR M, POX CP. Colorectal cancer. Lancet 2014; 383: 1490-1502. https:/doi.org/10.1016/S0140-6736(13)61649-9

[3] SADANANDAM A, LYSSIOTIS CA, HOMICSKO K, COLLISSON EA, GIBB WJ et al. A colorectal cancer classification system that associates cellular phenotype and responses to therapy. Nat Med 2013; 19: 619-625. https:/doi.org/10.1038/ nm. 3175

[4] ANDRE T, BONI C, MOUNEDJI-BOUDIAF L, NAVARRO $\mathrm{M}$, TABERNERO $\mathrm{J}$ et al. Oxaliplatin, fluorouracil, and leucovorin as adjuvant treatment for colon cancer. New England Journal of Medicine 2004; 350: 2343-2351. https:/ doi.org/10.1056/NEJMoa032709

[5] NISHIHARA R, WU K, LOCHHEAD P, MORIKAWA T, LIAO X et al. Long-term colorectal-cancer incidence and mortality after lower endoscopy. N Engl J Med 2013; 369: 1095-1105. https:/doi.org/10.1056/NEJMoa1301969

[6] HAJMANOOCHEHRI F, ASEFZADEH S, KAZEMIFAR AM, EBTEHAJ M. Clinicopathological features of colon adenocarcinoma in Qazvin, Iran: a 16 year study. Asian Pacific journal of cancer prevention: Asian PacJ Cancer Prev 2014; 15: 951-955. https:/doi.org/10.7314/APJCP.2014.15.2.951

[7] LING H, FABBRI M, CALIN GA. MicroRNAs and other noncoding RNAs as targets for anticancer drug development. Nat Rev Drug Discov 2013; 12: 847-865. https:/doi.org/10.1038/ $\underline{\text { nrd4140 }}$

[8] CALIN GA, SEVIGNANI C, DUMITRU CD, HYSLOP T, $\mathrm{NOCH} \mathrm{E}$ et al. Human microRNA genes are frequently located at fragile sites and genomic regions involved in cancers. Proc Natl Acad Sci USA 2004; 101: 2999-3004. https:/doi. org/10.1073/pnas.0307323101

[9] BARTEL DP. MicroRNAs: genomics, biogenesis, mechanism, and function. Cell 2004; 116: 281-297. https:/doi.org/10.1016/ $\underline{\text { S0092-8674(04)00045-5 }}$

[10] FARAZI TA, HOELL JI, MOROZOV P, TUSCHL T. MicroRNAs in Human Cancer. p 1-20. In: U. Schmitz, O. Wolkenhauer and J. Vera (Eds.), MicroRNA Cancer Regulation, Springer Netherlands, 2013, ISBN 978-94-0075590-1.

[11] IORIO MV, CROCE CM. microRNA involvement in human cancer. Carcinogenesis 2012; 33: 1126-1133. https:/doi. org/10.1093/carcin/bgs140

[12] LU J, GETZ G, MISKA EA, ALVAREZ-SAAVEDRA E, LAMB J et al. MicroRNA expression profiles classify human cancers. Nature 2005; 435: 834-838. https:/doi.org/10.1038/ nature03702

[13] ZEN K, ZHANG CY. Circulating microRNAs: a novel class of biomarkers to diagnose and monitor human cancers. Med Res Rev 2012; 32: 326-348. https:/doi.org/10.1002/med.20215

[14] KIDA Y, HAN YP. MicroRNA expression in colon adenocarcinoma. JAMA 2008; 299: 2628. https:/doi.org/10.1001/ jama.299.22.2628-a

[15] SCHETTER AJ, LEUNG SY, SOHN JJ, ZANETTI KA, BOWMAN ED et al. MicroRNA expression profiles associated with prognosis and therapeutic outcome in colon adenocarcinoma. JAMA 2008; 299: 425-436. https:/doi.org/10.1001/ jama.299.4.425

[16] HERZIG DO, TSIKITIS VL. Molecular markers for colon diagnosis, prognosis and targeted therapy. J Surg Oncol 2015; 111: 96-102. https:/doi.org/10.1002/jso.23806

[17] Weissmann-Brenner A, Kushnir M, Lithwick Yanai G, Aharonov R, Gibori $\mathrm{H}$ et al. Tumor microRNA-29a expression and the risk of recurrence in stage II colon cancer. Int J Oncol 2012; 40: 2097-2103.

[18] JIANG H, ZHANG G, WU JH, JIANG CP. Diverse roles of miR-29 in cancer (review). Oncol Rep 2014; 31: 1509-1516. https:/doi.org/10.3892/or.2014.3036

[19] ZHAO Y, SIMON R. BRB-ArrayTools Data Archive for human cancer gene expression: a unique and efficient data sharing resource. Cancer Inform 2008; 6: 9-15.

[20] GE YZ, XIN H, LU TZ, XU Z, YU P et al. MicroRNA expression profiles predict clinical phenotypes and prognosis in 
chromophobe renal cell carcinoma. Sci Rep 2015; 5: 10328. https:/doi.org/10.1038/srep10328

[21] HE S, ZENG S, ZHOU ZW, HE ZX, ZHOU SF. Hsa-microRNA-181a is a regulator of a number of cancer genes and a biomarker for endometrial carcinoma in patients: a bioinformatic and clinical study and the therapeutic implication. Drug Des Devel Ther 2015; 9: 1103-1175.

[22] ZHANG J, CHONG CC, CHEN GG, LAI PB. A SevenmicroRNA Expression Signature Predicts Survival in Hepatocellular Carcinoma. PLoS ONE 2015; 10: e0128628. https:/doi.org/10.1371/journal.pone.0128628

[23] PAI RK, JAYACHANDRAN P, KOONG AC, CHANG DT, KWOK S et al. BRAF-mutated, microsatellite-stable adenocarcinoma of the proximal colon: an aggressive adenocarcinoma with poor survival, mucinous differentiation, and adverse morphologic features. Am J Surg Pathol 2012; 36: 744-752. https:/doi.org/10.1097/PAS.0b013e31824430d7

[24] JASS J. Classification of colorectal cancer based on correlation of clinical, morphological and molecular features. Histopathology 2007; 50: 113-130. https:/doi.org/10.1111/ j.1365-2559.2006.02549.x

[25] SCHNEIDER EB, HYDER O, BROOKE BS, EFRON J, CAMERON JL et al. Patient readmission and mortality after colorectal surgery for colon cancer: impact of length of stay relative to other clinical factors. J Am Coll Surg 2012; 214: 390-398. https:/doi.org/10.1016/j.jamcollsurg.2011.12.025

[26] PHIPPS AI, BUCHANAN DD, MAKAR KW, WIN AK, BARON JA et al. KRAS-mutation status in relation to colorectal cancer survival: the joint impact of correlated tumour markers. Br J Cancer 2013; 108: 1757-1764. https:/doi.org/10.1038/ bjc. 2013.118

[27] SCHEPELER T, REINERT JT, OSTENFELD MS, CHRISTENSEN LL, SILAHTAROGLU AN et al. Diagnostic and prognostic microRNAs in stage II colon cancer. Cancer Res 2008; 68: 6416-6424. https:/doi.org/10.1158/0008-5472.CAN07-6110

[28] IORIO MV, CROCE CM. MicroRNA dysregulation in cancer: diagnostics, monitoring and therapeutics. A comprehensive review. EMBO Mol Med 2012; 4: 143-159. https:/doi. org/10.1002/emmm.201100209

[29] LEWIS BP, BURGE CB, BARTEL DP. Conserved seed pairing, often flanked by adenosines, indicates that thousands of human genes are microRNA targets. Cell 2005; 120: 15-20. https:/doi.org/10.1016/j.cell.2004.12.035

[30] YATES LA, NORBURY CJ, GILBERT RJ. The long and short of microRNA. Cell 2013; 153: 516-519. https:/doi.org/10.1016/j. cell.2013.04.003

[31] ZHOU J, ZHOU Y, YIN B, HAO W, ZHAO L et al. 5-Fluorouracil and oxaliplatin modify the expression profiles of microRNAs in human colon cancer cells in vitro. Oncol Rep 2010; 23: 121-128.

[32] XU XT, XU Q, TONG JL, ZHU MM, NIE F et al. MicroRNA expression profiling identifies miR-328 regulates cancer stem cell-like SP cells in colorectal cancer. Br J Cancer 2012; 106: 1320-1330. https:/doi.org/10.1038/bjc.2012.88

[33] YANAIHARA N, CAPLEN N, BOWMAN E, SEIKE M, KUMAMOTO K et al. Unique microRNA molecular profiles in lung cancer diagnosis and prognosis. Cancer Cell 2006; 9: 189-198. https:/doi.org/10.1016/j.ccr.2006.01.025

[34] BAI Y, WANG YL, YAO WJ, GUO L, XI HF et al. Expression of miR-32 in human non-small cell lung cancer and its correlation with tumor progression and patient survival. Int J Clin Exp Pathol 2015; 8: 824-829.

[35] YAN SY, CHEN MM, LI GM, WANG YQ, FAN JG. MiR32 induces cell proliferation, migration, and invasion in hepatocellular carcinoma by targeting PTEN. Tumour Biol 2015; 36: 4747-4755. https:/doi.org/10.1007/s13277-015$\underline{3124-9}$

[36] CHEN S, ZHU J, YU F, TIAN Y, MA S et al. Combination of miRNA and RNA functions as potential biomarkers for gastric cancer. Tumour Biol 2015; 36: 9909-9918. https:/doi. org/10.1007/s13277-015-3756-9

[37] MORRISON CD, PARVANI JG, SCHIEMANN WP. The relevance of the TGF-beta paradox to EMT-MET programs. Cancer Lett 2013; 341: 30-40. https:/doi.org/10.1016/j. canlet.2013.02.048

[38] MEULMEESTER E, TEN DIJKE P. The dynamic roles of TGF-beta in cancer. J Pathol 2011; 223: 205-218. https:/doi. org/10.1002/path.2785

[39] MENG X, JOOSSE SA, MÜLLER V, TRILLSCH F, MILDELANGOSCH K et al. Diagnostic and prognostic potential of serum miR-7, miR-16, miR-25, miR-93, miR-182, miR-376a and miR-429 in ovarian cancer patients. Br J Cancer 2015; 113: 1358-1366. https:/doi.org/10.1038/bjc.2015.340 
Table S1. Summary of differentially expressed microRNAs between cancer and adjacent tissues.

\begin{tabular}{|c|c|c|c|c|c|}
\hline \multirow[t]{2}{*}{ MicroRNA } & \multicolumn{2}{|c|}{ Expression Level $^{\text {a }}$} & \multirow[t]{2}{*}{ Fold Change } & \multirow[t]{2}{*}{$P$ value } & \multirow[t]{2}{*}{ FDR } \\
\hline & Tumor & Adjacent & & & \\
\hline hsa-mir-423 & 65.21 & 636.12 & 0.10245902 & $<1 \mathrm{e}-07$ & $<1 \mathrm{e}-07$ \\
\hline hsa-mir-141 & 1267.28 & 34.11 & 37.037037 & $<1 \mathrm{e}-07$ & $<1 \mathrm{e}-07$ \\
\hline hsa-mir-182 & 13598.48 & 390.03 & 34.4827586 & $<1 \mathrm{e}-07$ & $<1 \mathrm{e}-07$ \\
\hline hsa-mir-378 & 528.42 & 5851.17 & 0.09033424 & $<1 \mathrm{e}-07$ & $<1 \mathrm{e}-07$ \\
\hline hsa-mir-19b-2 & 141.94 & 0.68 & 208.333333 & $<1 \mathrm{e}-07$ & $<1 \mathrm{e}-07$ \\
\hline hsa-mir-16-1 & 705.55 & 21.08 & 33.3333333 & $<1 \mathrm{e}-07$ & $<1 \mathrm{e}-07$ \\
\hline hsa-mir-582 & 370.76 & 4.25 & 90.9090909 & $<1 \mathrm{e}-07$ & $<1 \mathrm{e}-07$ \\
\hline hsa-mir-98 & 36.21 & 0.86 & 41.6666667 & $<1 \mathrm{e}-07$ & $<1 \mathrm{e}-07$ \\
\hline hsa-mir-328 & 14.71 & 346.45 & 0.04246285 & $<1 \mathrm{e}-07$ & $<1 \mathrm{e}-07$ \\
\hline hsa-mir-374a & 675.62 & 2.21 & 303.030303 & $<1 \mathrm{e}-07$ & $<1 \mathrm{e}-07$ \\
\hline hsa-mir-203 & 20718.08 & 631.04 & 33.3333333 & $<1 \mathrm{e}-07$ & $<1 \mathrm{e}-07$ \\
\hline hsa-mir-126 & 2562.93 & 97.79 & 26.3157895 & $<1 \mathrm{e}-07$ & $<1 \mathrm{e}-07$ \\
\hline hsa-mir-142 & 3219.77 & 14.51 & 222.222222 & $<1 \mathrm{e}-07$ & $<1 \mathrm{e}-07$ \\
\hline hsa-mir-1180 & 3.76 & 79.41 & 0.04730369 & $<1 \mathrm{e}-07$ & $<1 \mathrm{e}-07$ \\
\hline hsa-mir-542 & 138.18 & 1.26 & 109.89011 & $<1 \mathrm{e}-07$ & $<1 \mathrm{e}-07$ \\
\hline hsa-mir-29b-1 & 445.17 & 4.61 & 100.4908 & $<1 \mathrm{e}-07$ & $<1 \mathrm{e}-07$ \\
\hline hsa-mir-101-1 & 5942.65 & 103.44 & 58.8235294 & $<1 \mathrm{e}-07$ & $<1 \mathrm{e}-07$ \\
\hline hsa-mir-574 & 27.06 & 391.86 & 0.06906077 & $<1 \mathrm{e}-07$ & $<1 \mathrm{e}-07$ \\
\hline hsa-mir-152 & 212.96 & 8.42 & 25.7294 & $<1 \mathrm{e}-07$ & $<1 \mathrm{e}-07$ \\
\hline hsa-let-7b & 11906.26 & 97941.41 & 0.12150668 & $<1 \mathrm{e}-07$ & $<1 \mathrm{e}-07$ \\
\hline hsa-mir-1976 & 3.07 & 73.54 & 0.04177109 & $<1 \mathrm{e}-07$ & $<1 \mathrm{e}-07$ \\
\hline hsa-mir-193a & 78.68 & 789.28 & 0.0997009 & $<1 \mathrm{e}-07$ & $<1 \mathrm{e}-07$ \\
\hline hsa-mir-335 & 148.8 & 3.39 & 43.4782609 & $<1 \mathrm{e}-07$ & $<1 \mathrm{e}-07$ \\
\hline hsa-mir-197 & 136.84 & 4595.45 & 0.02977963 & $<1 \mathrm{e}-07$ & $<1 \mathrm{e}-07$ \\
\hline hsa-mir-26a-1 & 10.79 & 0.53 & 20.4081633 & $<1 \mathrm{e}-07$ & $<1 \mathrm{e}-07$ \\
\hline hsa-mir-20a & 345.99 & 8.56 & 40.65392 & $<1 \mathrm{e}-07$ & $<1 \mathrm{e}-07$ \\
\hline hsa-mir-106a & 47.42 & 1.18 & 40.83096 & $<1 \mathrm{e}-07$ & $<1 \mathrm{e}-07$ \\
\hline hsa-mir-324 & 19.56 & 96.96 & 0.2016129 & $<1 \mathrm{e}-07$ & $<1 \mathrm{e}-07$ \\
\hline hsa-let-7d & 500.2 & 4547.88 & 0.110011 & $<1 \mathrm{e}-07$ & $<1 \mathrm{e}-07$ \\
\hline hsa-mir-148a & 75911.95 & 3768.94 & 20.10935 & $<1 \mathrm{e}-07$ & $<1 \mathrm{e}-07$ \\
\hline hsa-mir-379 & 656.61 & 25.1 & 26.3157895 & $<1 \mathrm{e}-07$ & $<1 \mathrm{e}-07$ \\
\hline hsa-mir-199b & 4325.75 & 228.74 & 18.8679245 & $<1 \mathrm{e}-07$ & $<1 \mathrm{e}-07$ \\
\hline hsa-mir-766 & 3.26 & 61.19 & 0.0532198 & $<1 \mathrm{e}-07$ & $<1 \mathrm{e}-07$ \\
\hline hsa-mir-101-2 & 14.69 & 0.54 & 27.027027 & $<1 \mathrm{e}-07$ & $6.55 \mathrm{E}-07$ \\
\hline hsa-mir-29b-2 & 483 & 40.45 & 11.9047619 & $<1 \mathrm{e}-07$ & $6.55 \mathrm{E}-07$ \\
\hline hsa-mir-452 & 59.68 & 1.53 & 38.4615385 & $<1 \mathrm{e}-07$ & $6.55 \mathrm{E}-07$ \\
\hline hsa-mir-429 & 218.79 & 19.45 & 11.2359551 & $1.00 \mathrm{E}-07$ & $6.55 \mathrm{E}-07$ \\
\hline hsa-let-7a-3 & 2907.3 & 12417.59 & 0.23419204 & $2.00 \mathrm{E}-07$ & $1.19 \mathrm{E}-06$ \\
\hline hsa-mir-19b-1 & 13.78 & 0.4 & 34.4827586 & $2.00 \mathrm{E}-07$ & 1.19E-06 \\
\hline hsa-mir-375 & 15165.46 & 239661.69 & 0.06329114 & $2.00 \mathrm{E}-07$ & $1.19 \mathrm{E}-06$ \\
\hline
\end{tabular}




\begin{tabular}{|c|c|c|c|c|c|}
\hline hsa-let-7a-1 & 2852.36 & 11482.82 & 0.24813896 & 2.00E-07 & $1.19 \mathrm{E}-06$ \\
\hline hsa-mir-652 & 13.06 & 59.33 & 0.22026432 & $3.00 \mathrm{E}-07$ & $1.56 \mathrm{E}-06$ \\
\hline hsa-mir-199a-1 & 1602.3 & 183.74 & 9.09090909 & $3.00 \mathrm{E}-07$ & $1.56 \mathrm{E}-06$ \\
\hline hsa-mir-199a-2 & 2988.74 & 265.91 & 11.2359551 & $3.00 \mathrm{E}-07$ & $1.56 \mathrm{E}-06$ \\
\hline hsa-mir-17 & 1039.39 & 94.52 & 10.989011 & $3.00 \mathrm{E}-07$ & $1.56 \mathrm{E}-06$ \\
\hline hsa-mir-200c & 6221.95 & 33750.22 & 0.18450185 & $3.00 \mathrm{E}-07$ & $1.56 \mathrm{E}-06$ \\
\hline hsa-mir-144 & 55.61 & 0.65 & 83.3333333 & $3.00 \mathrm{E}-07$ & $1.56 \mathrm{E}-06$ \\
\hline hsa-mir-139 & 26.83 & 595.79 & 0.04502476 & 4.00E-07 & $2.03 \mathrm{E}-06$ \\
\hline hsa-mir-589 & 29.17 & 170.66 & 0.17094017 & $5.00 \mathrm{E}-07$ & 2.39E-06 \\
\hline hsa-mir-30e & 11449.76 & 1846.59 & 6.252009 & $5.00 \mathrm{E}-07$ & 2.39E-06 \\
\hline hsa-mir-1306 & 2.65 & 60.15 & 0.04409171 & $5.00 \mathrm{E}-07$ & 2.39E-06 \\
\hline hsa-mir-136 & 59.75 & 0.73 & 83.3333333 & $6.00 \mathrm{E}-07$ & $2.77 \mathrm{E}-06$ \\
\hline hsa-mir-125a & 293.85 & 2805.77 & 0.10471204 & $6.00 \mathrm{E}-07$ & $2.77 \mathrm{E}-06$ \\
\hline hsa-mir-660 & 25.85 & 1.3 & 20.37497 & $7.00 \mathrm{E}-07$ & $3.06 \mathrm{E}-06$ \\
\hline hsa-let-7a-2 & 7409.83 & 25070.24 & 0.29585799 & $7.00 \mathrm{E}-07$ & $3.06 \mathrm{E}-06$ \\
\hline hsa-mir-1266 & 4.74 & 29.97 & 0.15822785 & $7.00 \mathrm{E}-07$ & $3.06 \mathrm{E}-06$ \\
\hline hsa-mir-92b & 28.45 & 323.2 & 0.08802817 & 8.00E-07 & $3.43 \mathrm{E}-06$ \\
\hline hsa-mir-10a & 53382.96 & 7757.98 & 6.666666667 & $9.00 \mathrm{E}-07$ & $3.80 \mathrm{E}-06$ \\
\hline hsa-mir-92a-2 & 9256.72 & 57133.31 & 0.16207455 & $1.30 \mathrm{E}-06$ & $5.22 \mathrm{E}-06$ \\
\hline hsa-mir-181a-1 & 605.37 & 6230.26 & 0.09718173 & $1.30 \mathrm{E}-06$ & 5.22E-06 \\
\hline hsa-mir-374b & 32.43 & 1.56 & 20.8333333 & $1.30 \mathrm{E}-06$ & $5.22 \mathrm{E}-06$ \\
\hline hsa-mir-140 & 399.89 & 1637.69 & 0.24390244 & $1.50 \mathrm{E}-06$ & $5.93 \mathrm{E}-06$ \\
\hline hsa-mir-340 & 10.07 & 1.17 & 8.33333333 & $1.60 \mathrm{E}-06$ & $6.22 \mathrm{E}-06$ \\
\hline hsa-mir-424 & 86.27 & 1.09 & 76.9230769 & $1.90 \mathrm{E}-06$ & $7.28 \mathrm{E}-06$ \\
\hline hsa-mir-92a-1 & 375.16 & 2815.5 & 0.13333333 & 2.00E-06 & 7.32E-06 \\
\hline hsa-mir-150 & 270.22 & 3745.44 & 0.07215007 & $2.00 \mathrm{E}-06$ & 7.32E-06 \\
\hline hsa-mir-15a & 90.52 & 5.36 & 16.9491525 & $2.00 \mathrm{E}-06$ & 7.32E-06 \\
\hline hsa-mir-1307 & 1078.6 & 9451.56 & 0.11415525 & $2.10 \mathrm{E}-06$ & $7.58 \mathrm{E}-06$ \\
\hline hsa-mir-183 & 7036.58 & 899.5 & 7.69230769 & 2.70E-06 & $9.60 \mathrm{E}-06$ \\
\hline hsa-mir-744 & 27.65 & 114.43 & 0.24154589 & $3.20 \mathrm{E}-06$ & $1.12 \mathrm{E}-05$ \\
\hline hsa-mir-99b & 18129.17 & 94070.15 & 0.19267823 & 4.00E-06 & $1.38 \mathrm{E}-05$ \\
\hline hsa-mir-628 & 42.84 & 0.42 & 102.040816 & 4.50E-06 & $1.53 \mathrm{E}-05$ \\
\hline hsa-mir-671 & 3.4 & 22.18 & 0.15360983 & 4.60E-06 & $1.55 \mathrm{E}-05$ \\
\hline hsa-mir-196b & 3664.06 & 396.47 & 9.09090909 & $6.10 \mathrm{E}-06$ & $2.03 \mathrm{E}-05$ \\
\hline hsa-let-7f-1 & 9.19 & 1.22 & 7.69230769 & $6.50 \mathrm{E}-06$ & $2.13 \mathrm{E}-05$ \\
\hline hsa-mir-153-2 & 32.08 & 0.57 & 55.5555556 & $7.90 \mathrm{E}-06$ & $2.55 \mathrm{E}-05$ \\
\hline hsa-mir-151 & 1431.77 & 477.39 & 3.03030303 & 8.60E-06 & $2.75 \mathrm{E}-05$ \\
\hline hsa-mir-32 & 20.14 & 1.29 & 15.625 & $1.02 \mathrm{E}-05$ & $3.21 \mathrm{E}-05$ \\
\hline hsa-mir-361 & 126.94 & 496.56 & 0.25575448 & $1.05 \mathrm{E}-05$ & $3.27 \mathrm{E}-05$ \\
\hline hsa-mir-15b & 97.53 & 631.27 & 0.15455951 & $1.18 \mathrm{E}-05$ & $3.63 \mathrm{E}-05$ \\
\hline hsa-mir-24-2 & 1383.13 & 265.79 & 5.26315789 & $1.26 \mathrm{E}-05$ & $3.83 \mathrm{E}-05$ \\
\hline hsa-mir-1296 & 1.29 & 24.93 & 0.05167959 & $1.31 \mathrm{E}-05$ & $3.93 \mathrm{E}-05$ \\
\hline hsa-mir-484 & 38.06 & 181.49 & 0.20964361 & $1.37 \mathrm{E}-05$ & $4.06 \mathrm{E}-05$ \\
\hline
\end{tabular}




\begin{tabular}{|c|c|c|c|c|c|}
\hline hsa-let-7f-2 & 3102.88 & 373.88 & 8.33333333 & $1.46 \mathrm{E}-05$ & $4.28 \mathrm{E}-05$ \\
\hline hsa-mir-30b & 148.68 & 20.74 & 7.14285714 & $1.62 \mathrm{E}-05$ & 4.69E-05 \\
\hline hsa-mir-338 & 361.49 & 47.02 & 7.69230769 & $2.47 \mathrm{E}-05$ & 7.07E-05 \\
\hline hsa-mir-708 & 54.11 & 0.61 & 90.9090909 & 4.16E-05 & 0.000118 \\
\hline hsa-mir-874 & 10.8 & 60.97 & 0.17730496 & $4.45 \mathrm{E}-05$ & 0.000124 \\
\hline hsa-mir-145 & 2215.72 & 23665.56 & 0.09363296 & $4.50 \mathrm{E}-05$ & 0.000125 \\
\hline hsa-mir-10b & 35676.39 & 8227.69 & 4.34782609 & $5.44 \mathrm{E}-05$ & 0.000149 \\
\hline hsa-mir-7-1 & 27.69 & 2.85 & 10.293647 & $5.55 \mathrm{E}-05$ & 0.00015 \\
\hline hsa-mir-218-2 & 13.4 & 0.89 & 14.9253731 & $6.04 \mathrm{E}-05$ & 0.000162 \\
\hline hsa-mir-577 & 85.07 & 0.51 & 166.666667 & 7.22E-05 & 0.000191 \\
\hline hsa-mir-132 & 52.46 & 187.64 & 0.27932961 & $7.88 \mathrm{E}-05$ & 0.000207 \\
\hline hsa-mir-95 & 5.59 & 0.83 & 6.666666667 & 8.31E-05 & 0.000216 \\
\hline hsa-mir-185 & 35.71 & 10.8 & 3.33333333 & 8.70E-05 & 0.000223 \\
\hline hsa-mir-1468 & 1.27 & 13.51 & 0.09372071 & 8.91E-05 & 0.000224 \\
\hline hsa-mir-193b & 19.21 & 158.59 & 0.12106538 & 8.91E-05 & 0.000224 \\
\hline hsa-mir-196a-1 & 161.06 & 26.8 & 5.88235294 & $9.43 \mathrm{E}-05$ & 0.000235 \\
\hline hsa-mir-30d & 3412.72 & 10199.49 & 0.33444816 & $9.92 \mathrm{E}-05$ & 0.000245 \\
\hline hsa-mir-223 & 215.25 & 29.24 & 7.14285714 & 0.000115 & 0.000281 \\
\hline hsa-mir-188 & 2.52 & 0.51 & 5.296312 & 0.00016 & 0.000386 \\
\hline hsa-mir-552 & 38.97 & 2.24 & 17.2413793 & 0.000166 & 0.000398 \\
\hline hsa-mir-181d & 9.46 & 1.8 & 5.26315789 & 0.00017 & 0.000403 \\
\hline hsa-mir-339 & 19.18 & 86.07 & 0.22271715 & 0.000173 & 0.000405 \\
\hline hsa-mir-301a & 15.91 & 0.57 & 27.7777778 & 0.000174 & 0.000405 \\
\hline hsa-mir-1-2 & 36.7 & 0.74 & 50.782093 & 0.000183 & 0.000421 \\
\hline hsa-mir-186 & 249.24 & 63.59 & 3.84615385 & 0.000199 & 0.000453 \\
\hline hsa-mir-23a & 3165.31 & 1208.86 & 2.63157895 & 0.000222 & 0.000502 \\
\hline hsa-let-7g & 445.11 & 133.87 & 3.33333333 & 0.000242 & 0.000543 \\
\hline hsa-mir-330 & 7.76 & 28.83 & 0.26954178 & 0.000249 & 0.000554 \\
\hline hsa-mir-505 & 33.73 & 87.27 & 0.38610039 & 0.000279 & 0.000615 \\
\hline hsa-mir-26b & 379.75 & 82.39 & 4.54545455 & 0.00029 & 0.000633 \\
\hline hsa-mir-34a & 61.19 & 14.44 & 4.16666667 & 0.000298 & 0.000645 \\
\hline hsa-mir-133a-1 & 12.63 & 162.77 & 0.07757952 & 0.000306 & 0.000657 \\
\hline hsa-mir-337 & 23.77 & 1.45 & 16.3934426 & 0.000357 & 0.000759 \\
\hline hsa-mir-576 & 7.96 & 1.24 & 6.254326 & 0.000393 & 0.000829 \\
\hline hsa-mir-27a & 883.97 & 223.58 & 4.293648 & 0.000494 & 0.00103 \\
\hline hsa-mir-22 & 45125.04 & 16370.5 & 2.77777778 & 0.000515 & 0.00107 \\
\hline hsa-mir-590 & 24.02 & 0.35 & 66.66666667 & 0.000571 & 0.00117 \\
\hline hsa-mir-30a & 9018.02 & 2905.33 & 3.1253497 & 0.000605 & 0.00124 \\
\hline hsa-mir-200a & 1738.33 & 829.87 & 2.08333333 & 0.000693 & 0.0014 \\
\hline hsa-mir-539 & 17.71 & 3.83 & 4.54545455 & 0.000808 & 0.00162 \\
\hline hsa-mir-28 & 5013.11 & 10840.79 & 0.46296296 & 0.000823 & 0.00164 \\
\hline hsa-mir-451 & 136.62 & 22.89 & 5.88235294 & 0.00086 & 0.0017 \\
\hline hsa-mir-96 & 11.85 & 0.71 & 16.6666667 & 0.00088 & 0.00173 \\
\hline
\end{tabular}




\begin{tabular}{lccccc} 
hsa-mir-215 & 290.73 & 15.18 & 19.2307692 & 0.00091 & 0.00177 \\
hsa-mir-217 & 23.49 & 1.09 & 21.2765957 & 0.000935 & 0.00179 \\
hsa-mir-125b-1 & 191.76 & 1053.42 & 0.18214936 & 0.000937 & 0.00179 \\
\hline
\end{tabular}

FDR, false discovery rate

${ }^{a}$ mean expression data 
Table S2. MicroRNAs associated with the progression of colon adenocarcinoma

\begin{tabular}{|c|c|c|c|c|c|}
\hline MicroRNA & Expre & Level $^{\text {a }}$ & Fold Change & $P$ value & FDR \\
\hline AJCC stage & High stage & Low stage & & & \\
\hline hsa-mir-30a & 5742.86 & 4783.97 & 1.2 & 0.0055929 & 0.386 \\
\hline hsa-mir-625 & 320.23 & 407.28 & 0.79 & 0.0058302 & 0.386 \\
\hline hsa-mir-195 & 30.26 & 22.94 & 1.32 & 0.007238 & 0.386 \\
\hline hsa-mir-942 & 8.05 & 10.26 & 0.78 & 0.0073537 & 0.386 \\
\hline Pathologic T & $\mathrm{T3}+\mathrm{T} 4$ & $\mathrm{~T} 1+\mathrm{T} 2$ & & & \\
\hline hsa-mir-379 & 763.83 & 577.85 & 1.32 & 0.0041091 & 0.444 \\
\hline hsa-mir-337 & 23.37 & 18.25 & 1.28 & 0.0042134 & 0.444 \\
\hline hsa-let-7e & 540.85 & 401.66 & 1.35 & 0.0094846 & 0.444 \\
\hline hsa-mir-106a & 28.74 & 41.71 & 0.69 & 0.0095788 & 0.444 \\
\hline hsa-mir-493 & 12.62 & 9.83 & 1.28 & 0.0098845 & 0.444 \\
\hline Pathologic N & $\mathrm{N} 1+\mathrm{N} 2$ & No & & & \\
\hline hsa-mir-942 & 8.26 & 10.66 & 0.77 & 0.0020626 & 0.269 \\
\hline hsa-mir-30a & 5655.2 & 4778.2 & 1.18 & 0.0054794 & 0.269 \\
\hline hsa-mir-1-2 & 31.32 & 21 & 1.49 & 0.0066475 & 0.269 \\
\hline hsa-mir-125a & 289.01 & 240.97 & 1.2 & 0.0068128 & 0.269 \\
\hline hsa-mir-625 & 326.76 & 409.47 & 0.8 & 0.0070591 & 0.269 \\
\hline hsa-mir-146b & 416.02 & 501.99 & 0.83 & 0.0075198 & 0.269 \\
\hline hsa-mir-133a-1 & 13.59 & 9.1 & 1.49 & 0.0083855 & 0.269 \\
\hline hsa-mir-149 & 9.76 & 7.44 & 1.31 & 0.0090838 & 0.269 \\
\hline hsa-mir-629 & 104.19 & 121.09 & 0.86 & 0.0098188 & 0.269 \\
\hline Pathologic M & M1 & M0 & & & \\
\hline hsa-mir-96 & 22.2 & 14.52 & 1.53 & 0.0014243 & 0.253 \\
\hline hsa-mir-365-1 & 15.26 & 9.59 & 1.59 & 0.0020284 & 0.253 \\
\hline hsa-mir-337 & 28 & 20.85 & 1.34 & 0.0032715 & 0.253 \\
\hline hsa-mir-29b-1 & 465.81 & 363.38 & 1.28 & 0.0058784 & 0.253 \\
\hline hsa-mir-1307 & 1179.16 & 1476.49 & 0.80 & 0.0067812 & 0.253 \\
\hline hsa-mir-365-2 & 14.21 & 9.62 & 1.48 & 0.0073563 & 0.253 \\
\hline hsa-mir-29b-2 & 463.23 & 365.76 & 1.27 & 0.0080762 & 0.253 \\
\hline hsa-mir-625 & 277.31 & 380.32 & 0.73 & 0.0081321 & 0.253 \\
\hline hsa-mir-23b & 1277.04 & 1049.97 & 1.22 & 0.0092378 & 0.256 \\
\hline
\end{tabular}

FDR, false discovery rate

${ }^{\mathrm{a}}$ mean expression data 